being of a peculiar type, even when too far from the sun to show any colour. The clouds thus coloured are usually of a much striated or rippled structure, and show the colours generally in small spectra; whereas the clouds seen in December were remarkably smooth in texture, and although often striated, the striations were feeble and comparatively few, and in straight lines, while each cloud showed one regular gradation of colour.

Whether the coloured clouds described by your correspondents, with the exception of those mentioned by Mr. N., were all of the same kind, it is difficult to decide; perhaps they may have been so, in spite of the varieties in their appearance. Some observers describe the body of these clouds as having been dark, in particular your correspondents at Darlington and Broseley (Shropshire), Pp. 192, 193, whereas all seen here were white or bright. Still, those clouds seen further south were probably of the same kind, only thicker. The difference in shape is most likely not a radical one, as the larger clouds seen here had wavy, not straight, edges, though their general directions were the same as the sides of the more rectangular ones. The nearest approach here to a pallium of these singular clouds was on the morning of December 12, when there occurred, at $8.15 \mathrm{a} . \mathrm{m}$., an extensive pale steel blue film above the region where the sun was, and reaching to an altitude of $25^{\circ}$.

Dr. H. Geelmuyden, observing at Christiania on December 8 (see p. 264), appears to place the peculiar clouds at a lower level than cirro-cumulus, but as seen here they were always the highest clouds.

In conclusion, I think that Prof. A. S. Herschel is mistaken in supposing these clouds have been "only a good instance of a common sight," but although I never noticed them before, I do not dispute the suggestion of Dr. Geelmuyden that they may be seen more frequently than some of us have thought. I have not seen them since December I3.

Sunderland, February II

\section{Human Hibernation}

I DID not answer your correspondent's query on human hibernation in your issue of the 5 th inst. (p. 316 ), because I thought some one better informed than myself would answer it. However, as no one has done so, I may as well give a solution of this well-known Indian trick which I have seen, but the authority for which, I am sorry to say, I cannot remember. It is very simple, like all these things are when you "know how they are done." A tunnel is dug from the grave to the neighbouring jungle ; the grave itself is partly prepared. The subject is then, in sight of the spectators, prepared, by having his ears and nostrils filled with wax, and his tongue turned back. He is then apparently buried, creeps through the tunnel, and gets away. After six months, or any other interval, he creeps back again, is dug up apparently lifeless, and restored with infinite pains. In some cases, I believe, a sentry has been placed over the grave, but, of course, without results

Bolney House, Ennismore Gardens, S. W., February I3

\section{An Error in Ganot's "Physics"}

I BEG to call attention to a typical error in a formula which appears to have run through ten editions of Ganot's well-known treatise. It is one not difficult of discovery by that somewhat too rare class of students who carefully plod through all the steps which lead up to it, but very likely to be overlooked by the more common class who are content to extract the formula as it stands with the undoubting faith reasonably based on "Tenth Edition, revised and enlarged.'

The formula which represents the weight of air saturated with vapour occurs on p. 325 of the tenth edition, and is printed-

$$
P=\frac{0.31 \times V . F}{(I+\alpha t) 760}\left(H-\frac{3}{8} F\right) \text {. }
$$

The first $F$ should obviously be expunged.

$$
\text { E. Douglas Archibald }
$$

Tunbridge Wells, February 16

\section{Shadow on Clouds}

I AM not aware if the following phenomenon is at all common, but I venture to think it somewhat unusual, and th.t it might nterest some of your readers :-
Whilst at anchor in Cumberland Bay in the Island of Juan Fernandez on the evening of December 24,1884 , we observed the following remarkable sight. The Bay is situated on the north side of the island, and some way inland is a remarkable hill, called the "Yunkua," or "anvil," it being somewhat of the shape of one; it is the highest hill in the place, viz. 3005 feet, and from the anchorage bears about south-west, and is distant two miles. The Bay is closed in by high cliffs and hills. On the day mentioned, shortly after the sun had disappeared behind the western hills, we observed this hill make a distinct shadow on the clouds above it, in which every irregularity and peak came out with wonderful clearness. The shadow lasted till about $30^{\prime \prime}$ before the time of sunset (which was invisible to us), and was inverted and inclined to the hill as in a mirage at about $30^{\circ}$. The weather at the time was very fine. Barometer, $30^{\circ} 22$; temperature of altitude thermometer, F. $62^{\circ}$; and very few clouds were about.

H.M.S. Constance, at Sea, January 25

$$
\text { THE METEOROLOGY OF HAVANA }{ }^{1}
$$

THIS annual of the Royal College of the Society of Jesus at Havana for I 875, which has just been published, possesses more than a passing interest. The observations were made daily every two hours from 4 a.m. to Io p.m., and include pressure, temperature, humidity, wind, rain, magnetic, electric, optical, and other weather phenomena. The results are plotted on large monthly diagrams, and as each day has six-tenths of an inch devoted to it, the two-hourly observations of all the different elements can be readily seen and compared with each other; and this part of the work is done with a scrupulous care and accuracy it would not be easy to surpass. On the same diagrams are marked the days on which auroras are reported to have been observed in the United States, as published in the Monthly Weather Review at Washington.

A note is appended to each month's observations, drawing attention to the more significant of the magnetic perturbations in their relations to the changes of weather at the time, and in particular to the "nortes," or "northers," of the cooler months of the year. Thus, on April 3,4 , and 5 a "norther" prevailed, which was succeeded on the three following days by a remarkable magnetic perturbation, which was accompanied with a high barometer and a strong wind, rising in the afternoons to a rate of 35 kilometres per hour, with daily manifestations of aurora in the United States, but was unaccompanied throughout with any electric phenomena. Again, the magnetic perturbation, of April I 3 was coincident with a characteristic " norther," much thunder and lightning, a very heavy rainfall, and a disposition and state of the aqueous vapour which give rise to solar and lunar halos, and other optical effects; but during the time no auroras were reported from the United States. Father Viñes points out in the monthly notes various other relations between the magnetical and meteorological phenomena which suggest that this line of inquiry is likely to lead to valuable additions to our knowledge of weather changes.

The mean annual pressure at sea-level is $30^{\circ} 067$ inches, the maximum being $30^{\circ} 129$ inches in January and the minimum $30^{\circ} 002$ inches in September, with a secondary maximum of $30^{\circ} 092$ inches in July and minimum of $30^{\circ} 066$ inches in April. As regards the diurnal oscillation from the morning maximum to the afternoon minimum, the greatest occurs in the winter months, when it amounts to 0.080 inch, whereas in July it is only 0.05I inch. These diurnal and seasonal fluctuations in their varying amounts have no small significance in their relations to the analogous phenomena in the United States and over the high pressure area of the Atlantic. The mean annual temperature is $77^{\circ} 7$, rising to the maximum $82^{\circ} \cdot 2$ in July, and falling to the minimum $73^{\circ} \circ$ in December. The

I "Observaciones Magnéticas y Meteorólogicas del Real Colegio de Belen de la Compañia de Jesus en h Habana. Año de 1875 ." (Habana, 1884.) 
absolutely highest temperature, $9^{\circ} \cdot 8$, occurred at 4 p.m. on July 30 under very striking circumstances. For four days previously auroras had been observed in the United States; the magnetic and clectrical conditions showed marked disturbances at Havana; atmosphcric pressure, which had been low, began to rise on the 30 th, on which day, at 2 p.m., the relative humidity fell to 45 , but rose four hours after to 84 . The temperature, which at 4 p.m. was 98.8 , thereafter instantly and rapidly fell, and by 6 p.m liad fallen to $78^{\circ} \cdot 8$. The lowest tempcrature for the year, $55^{\circ} .9$, occurred at $6 \mathrm{am}$. on December 16 , at the termination of a "norther," which overspread the sky with cirri, attended with solar and lunar halos; and was immediately followed by a low barometer, remarkable hygrometric changes and irregularitics in the direction and velocity of the wind.

Excepting a greater tendency to southing during the warmer months, the wind varies little in direction from month to month. The diurnal variation is interesting. From 10 p.m. to 8 a.m. it is E. by S.; at ro a.m. E. by N. ; from Io a.m. to 2 p.m. N.N.E. ; 4 p.m. N.E. ; 6 p.m. E.N.E.; and at 8 p.m. E., thus showing in a marked manner the influence of the sea breeze at Havana. The daily changes in the wind's velocity are very large. The minimum occurs from 4 to 6 a.m., and the maximum from noon to 4 p.m., the maximum velocity being four times greater than the minimum. The strongest winds occur in April, and the weakest in November; the winds in April blowing with double the velocity of those in November. As regards direction, the strongest winds are the sea winds which blow from N.N.E. and E., and the weakest the land-winds from E.S.E., S.E., and S.W., the former blowing with double the force of the latter.

The annual curve of thunderstorms is a very decided one. Of the eighty recorded during 1875 , sixty-five occurred during the five months from May to September, and only three during the four months from January to March and December. The annual rainfall was 42.39 inches, about half of the whole amount falling in August and September, during which time $20 \% \mathrm{I}$ inches fell. Only a quarter of an inch fell in December, and half an inch in November. The total evaporation for the year was about 60 inches, the maximum, $6^{\circ} 92$ inches, being in April, when the air is driest and the winds strongest, and the minimum 3.60 inches in September, October, and November, when the air is most highly saturated and the force of the wind least. As regards the occurrence of rain at different periods of the day, more than 50 per cent. of the whole hours during which rain is noted to have fallen were between noon and 6 p.m., thus closely associating the rainfall with the diurnal period of the thunder storms. The almost total absence of the thunderstorm from the rains of the winter months, as compared with the summer months, when lightning, or some other clectric phenomenon occurs almost daily, is an important feature in the climate of Havana from its bearing on the theory of the thunderstorm.

\section{THE WHALE EXHIBITION IN HAMBURG}

\section{I)}

URING the autumn of last year an exhibition of considerable novelty and interest to zoologists was held in Hamburg, embracing complete skcletons, parts, and cranixe of whales, products of the same, and apparatus used for catching these greatest organisms of the world from the earliest times to the present day.

The suggestion for this exhibition came from the writer of thesc lines, who offered to exhibit three of the greatest fin-whale skelctons in existence. Dr. H. Bolau, director of the Zoological Gardens in Hamburg, succeeded, in spite of many obstacles, in arranging this exhibition and collecting interesting and valuable material, towards which Prof. Pagenstecher, director of the Natu- ral History Museum, also contributed greatly by arranging the cxhibits and obtaining several rare specimens acquired by the German Expedition of I882-83 to South Georgia. In this part were also some splendid watercolour drawings from this island, executed by Herr Mostlaff, which were greatly admired.

The exhibition, which was divided into four parts, viz. one for the whale fauna, one for the hunting-gear, one for the whale products, and one historic-ethnographical, took place partly in the open, partly in a hall.

In the first section, naturally, the Cetacer, were most prominent, these monsters being mounted in the Gardens. Of true Balienida, the Hamburg Zoological Muscum exhibited a cranium of Balcena mysticetus, L., a very fine specimen. Otherwise the Balanopteridæe, or fin-whales, were most numcrous, there being four different species of this family. The most imposing of them all was the skeleton of the "blue" whale (Balanoptera sibbaldii, Gray), the grcatest animal on earth. It measured 75 feet in length, and was mounted in its natural position. The specimen scemed to have been full grown, as no division between the epiphyse and the vertcbral body could be discovered. As an individual osteological curiosity may be mentioned that the jugal bone consisted of two bones, a smaller and a larger piece, which are closely united by strong ligaments.

Not far from this specimen stood the skeleton of the common fine-whale (Balconoptera musculus, Companyo), 63 feet long, which was, as P'rof. Flower describes it, " in adolescent state." The greater part of the thoracic and Jumbal vertebra showed distinct separation between the epiphyses and the vertebral body, which was also the casc with the limbs. Although the length between these two specics is not so very great, there is a marked difference between their structure. The fine-whale is remarkable for its lightness and elegance ; in proportion to its great length, some parts of the skeleton secm indeed quite fragile, whereas the blue whale shows throughout in its structure a massiveness bespeaking enormous muscular powers. The difference became even more striking when the fin-whale was compared with a third species, the Megaptera boops, O. Fabr. This skeleton was 54 feet long, and therefore a large individual, and was found dead at sea between the coasts of Norway and Russia. From the complete development of the ossification and coalescence of epiphyses with the vertebral bodies and respective diaphyses of the extremities it was clearly a full-grown animal. It gives an impression of heaviness, on account of the short, thick bones and the great length of the fore-limbs, I4-I 5 feet, which is very apparent. To this individual belongs the whale-bone complex, part of which was shown. Near the same a cranium of this species of whale was exhibited with a complete whale-bone complex. This was a very finc specimen, and was prepared for the Museum of Natural Sciences at Stuttgart, where it now is.

The above-mentioned skeletons and crania were prepared by me in 1883 at the whaling establishments at Vardö (1at. $70 \frac{1}{2}^{\circ} \mathrm{N}$.), but the three skeletons, which were, I may be permitted to say, very complete and fine specimens, I had stcamed and finished in Hamburg.

In the opon, too, there was mounted a skeleton of Balcenoptera rostrata, Fabr., the smallest of all finwhales; but this specimen left much to be desired in the way of completeness and finish. It was, however, interesting by its history and age, and is perhaps the oldest Cetacea in any museum. For 200 years it has been instated in the town hall at Bremen, where there is an inscription on the wall to the effect that the animal stranded at Bremerhafen on May 9, I669, whence it was brought to Bremen, and the skcleton accorded the abovementioned honour.

As representative of the great "tooth' whales, there was the lower jaw of a spermaceti whale belonging to an 